\title{
Microbial responses to chitin and chitosan in oxic and anoxic agricultural soil slurries
}

\author{
A. S. Wieczorek, S. A. Hetz, and S. Kolb \\ Department of Ecological Microbiology, University of Bayreuth, Bayreuth, Germany \\ Correspondence to: S. Kolb (steffen.kolb@uni-bayreuth.de)
}

Received: 23 January 2014 - Published in Biogeosciences Discuss.: 6 February 2014

Revised: 7 April 2014 - Accepted: 11 April 2014 - Published: 24 June 2014

\begin{abstract}
Microbial degradation of chitin in soil substantially contributes to carbon cycling in terrestrial ecosystems. Chitin is globally the second most abundant biopolymer after cellulose and can be deacetylated to chitosan or can be hydrolyzed to $N, N^{\prime}$-diacetylchitobiose and oligomers of $\mathrm{N}$-acetylglucosamine by aerobic and anaerobic microorganisms. Which pathway of chitin hydrolysis is preferred by soil microbial communities is unknown. Supplementation of chitin stimulated microbial activity under oxic and anoxic conditions in agricultural soil slurries, whereas chitosan had no effect. Thus, the soil microbial community likely was more adapted to chitin as a substrate. In addition, this finding suggested that direct hydrolysis of chitin was preferred to the pathway that starts with deacetylation. Chitin was apparently degraded by aerobic respiration, ammonification, and nitrification to carbon dioxide and nitrate under oxic conditions. When oxygen was absent, fermentation products (acetate, butyrate, propionate, hydrogen, and carbon dioxide) and ammonia were detected, suggesting that butyric and propionic acid fermentation, along with ammonification, were likely responsible for anaerobic chitin degradation. In total, 42 different chiA genotypes were detected of which twenty were novel at an amino acid sequence dissimilarity of less than $50 \%$. Various chiA genotypes responded to chitin supplementation and affiliated with a novel deep-branching bacterial chiA genotype (anoxic conditions), genotypes of Betaand Gammaproteobacteria (oxic and anoxic conditions), and Planctomycetes (oxic conditions). Thus, this study provides evidence that detected chitinolytic bacteria were catabolically diverse and occupied different ecological niches with regard to oxygen availability enabling chitin degradation under various redox conditions on community level.
\end{abstract}

\section{Introduction}

Chitin is a globally abundant biopolymer and is subject to rapid microbial turnover in the environment. Microbial degradation of chitin in soil substantially contributes to carbon cycling and release in terrestrial ecosystems (Gooday, 1990a). The biopolymer chitin consists of alternating $\beta-1$ 4-linked $N$-acetylglucosamine (GlcNAc) residues and is a structural component of many uni- and multicellular eukaryotes, such as fungi, protists, algae, and arthropods (Gooday, 1990a, b; Martínez et al., 2009). In aerated soils (i.e., including many agricultural soils), fungi and arthropods are the main sources of chitin. Soluble hydrolysis products are sources of energy, carbon, and/or nitrogen for chitinolytic and saccharolytic soil microorganisms (Gooday, 1990b; Keyhani and Roseman, 1999; Geisseler et al., 2010; Kellner and Vandenbol, 2010).

Chitin can be initially hydrolyzed by exo- and endochitinases (EC 3.2.1.14) to $N, N^{\prime}$-diacetylchitobiose ([GlcNAc $]_{2}$ ) and longer oligomers of GlcNAc. [GlcNAc] $]_{2}$ is subsequently cleaved (i.e., by $\beta-N$-acetylglucosaminidases; EC 3.2.1.30) into $\mathrm{N}$-acetylglucosamine (GlcNAc). An alternative hydrolysis pathway starts with the deacetylation of chitin to chitosan that is then hydrolyzed to glucosamine $(\mathrm{GlcN})$ by chitosanases (EC 3.2.1.132) and glucosaminidases (EC 3.2.1.30) (Gooday, 1990b; Beier and Bertilsson, 2013). Two previous studies suggested that the hydrolysis via initial deacetylation might be predominant in estuarine sediments (Hillman et al., 1989a, b). Nonetheless, for aquatic and terrestrial ecosystems it has not been evaluated which chitin hydrolysis pathway prevails in microbial communities (Beier and Bertilsson, 2013). Deacetylation of chitin would produce chitosan, which is less abundant in nature than chitin (Gooday, 1990a; Raafat et al., 2008) and known to be toxic for 
microorganisms in pure culture (Raafat et al., 2008; Šimůnek et al., 2012). Therefore, the degradation pathway that starts with deacetylation is likely not a dominant mechanism of chitin hydrolysis on the community level.

Cultured chitinolytic bacteria are members of Acidobacteria, Actinobacteria, Bacteriodetes (Cytophaga), Betaproteobacteria, Gammaproteobacteria, and Firmicutes (Gooday, 1990b; Yang et al., 2005; Someya et al., 2011; Foesel et al., 2013). Detection of genes encoding selected chitinases has been employed in soils and other environments to assess chitinolytic bacteria at the community level (Cottrell et al., 1999; Ramaiah et al., 2000; Williamson et al., 2000; Metcalfe et al., 2002; LeCleir et al., 2004, 2007; Hobel et al., 2005; Xiao et al., 2005; Hjort et al., 2010; Beier et al., 2011b; Peter et al., 2011; Cretoiu et al., 2012; Köllner et al., 2012; Beier and Bertilsson 2013; Kielak et al., 2013). A single bacterium can harbor multiple copies and also various different chitinase genes, for example, Streptomyces coelicolor A3 possesses nine genes of glycoside hydrolases family (GH) 18 chitinases and two of GH 19 (Saito et al., 2003). In total, there are over 100 enzyme families of glycoside hydrolases which can be distinguished. Nonetheless, most of the known hydrolases that attack chitin (i.e., so-called chitinases) belong to GH 18 or 19 , whereby the latter is mainly restricted to plants. GH 18 is dominated by chitinase genes of chitinolytic Bacteria (Cohen-Kupiec and Chet, 1998; Karlsson and Stenlid, 2009). Few chitinase-like proteins are affiliated with GH 23 and 48 (Fujita et al., 2006; Arimori et al., 2013). GH 18 is divided into subfamilies A, B, and C (Henrissat and Bairoch, 1993; Suzuki et al., 1999; Cantarel et al., 2009; Karlsson and Stenlid, 2009). Established primers that have been used for environmental detection of microbial chitin degraders were designed to target chitinase genes belonging to subfamily A of GH 18 (i.e., the so-called chiA gene) (Williamson et al., 2000; Metcalfe et al., 2002; LeCleir et al., 2004; Hobel et al., 2005; Xiao et al., 2005). Beyond their role in the degradation of chitin through soil microorganisms, chitinases are involved in formation and changes of cell walls of fungi and the exoskeleton of arthropods, or can act in plants as a defense system against pathogens (Gooday, 1990b; Patil et al., 2000; Kasprzewska, 2003; Seidl, 2008). The large diversity of known chiA genotypes that has been discovered in each previous environmental study reflects the broad functional and large organismal diversity. However, many genotypes might not have been discovered to date (Beier and Bertilsson, 2013; Kielak et al., 2013).

The majority of known chiA genotypes that have been detected in soil affiliate with Actinobacteria and to a minor extent with Firmicutes (Metcalfe et al., 2002, Ikeda et al., 2007, Hjort et al., 2010). In contrast to this general finding, supplementation of shrimp shell residues to agricultural soil can stimulate a rapid response of Beta- and Gammaproteobacterial chiA-like genotypes, suggesting that not only wellknown microbial chitin degraders can be relevant for chitin degradation in soil (Kielak et al., 2013).
Soil type, water content, temperature, substrate availability, and most significantly soil $\mathrm{pH}$ are environmental factors known to influence soil chitinolytic communities (Manucharova et al., 2006, 2011; Terahara et al., 2009; Yaroslavtsev et al., 2009; Kielak et al., 2013). Oxygen availability is another important factor that affects soil microbial communities. Oxygen distribution is heterogeneous and dynamic, and depends on moisture, aggregate size, and properties of biogeochemical interfaces in aerated soils (Or et al., 2007). Aerated agricultural soils are largely oxic. Nonetheless, microbial anaerobiosis occurs in microzones of such soils (Küsel and Drake, 1995; Wagner et al.,1996; Picek et al., 2000; Pett-Ridge and Firestone, 2005), and presence or absence of oxygen can differentially impact the stimulation of microbial processes involved in the degradation of the biopolymer cellulose in aerated agricultural soil, consequently leading to different active bacterial taxa (Schellenberger et al., 2010, 2011, 2012). Thus, contrasting energyconserving microbial metabolisms occurring at close proximity to each other can simultaneously contribute to the overall degradation of biopolymers in soil.

Aforementioned considerations suggest (i) that chitin in the investigated soil is not primarily hydrolyzed via deacetylation to chitosan, (ii) that previously unknown chiA genotypes occur, and (iii) that different chitinolytic taxa are active under oxic and anoxic conditions in aerated agricultural soil. These three hypotheses were tested by investigation of oxic and anoxic soil slurries of a temperate agricultural soil that were either supplemented with chitin or chitosan. Microbial processes associated with chitin and chitosan hydrolysis and degradation were determined, and metabolic responses and identities of chitinolytic microorganisms were assessed by analyzing the marker gene chiA.

\section{Materials and methods}

\subsection{Sampling site and soil properties}

The upper $20 \mathrm{~cm}$ layer of an aerated agricultural soil was sampled in April 2011 and April 2012, and stored under dark and moist conditions at $2{ }^{\circ} \mathrm{C}$, and processed within a week. The sampling site is located on the research farm Klostergut Scheyern near Munich, Germany $\left(48^{\circ} 30.0^{\prime} \mathrm{N}, 11^{\circ} 20.7^{\prime} \mathrm{E}\right)$. The mean annual precipitation was $803 \mathrm{~mm}$ with a mean temperature of $7.4^{\circ} \mathrm{C}$ over a 30 year period (Sommer et al., 2003). The soil type was a Dystric Cambisol (FAO classification system) (Fuka et al., 2008). 


\subsection{Chitin, chitosan, $N, N^{\prime}$-diacetylchitobiose, $N$-acetylglucosamine, and glucosamine supplemented soil slurries}

Soil slurries were prepared by mixing soil with sterile oxic or anoxic water (ratio $1: 2.5$ ) in a total volume of one litre in sterile rubber-stoppered 2-litre-flasks. Soil from April 2011 was used in experiments with GlcNAc and GlcN, and soil sampled in April 2012 was used in experiments with chitin, chitosan, and $[\mathrm{GlcNAc}]_{2}$. Slurries were placed on ice and flushed with sterile argon (100\%, Riessner-Gase$\mathrm{GmbH}$, Lichtenfels, Germany) or sterile air for one hour. Soil slurries were homogenized on an end-over-end shaker for $1.5 \mathrm{~h}$ at $5^{\circ} \mathrm{C}$ and were then divided in $80 \mathrm{~mL}$ aliquots in rubber-stoppered $0.5 \mathrm{~L}$ flasks with sterile argon or air as atmosphere. Treatments were conducted in triplicates. For chitin- and chitosan-supplemented slurries, $0.2 \mathrm{~g}$ of ground chitin or chitosan (acetylation degree $\geq 95 \%$ and $15-25 \%$, respectively) (Sigma-Aldrich ${ }^{\circledR} \mathrm{GmbH}$, Germany) was added at the onset of incubation. The applied amount of biopolymers was similar to the added amount of cellulose to soil slurries of the same site in a previous study (Schellenberger et al., 2010). Chitin- and chitosan-treatments were incubated for 41 days as these substrates are large, sterile, and insoluble crystals, which need to be colonized and hydrolyzed before they can be utilized as a carbon, nitrogen, and energy source, that is, a process that is much slower than the microbial degradation of soluble hydrolysis products of these biopolymers. Such soluble N-sugars were supplemented with a final concentration of $250 \mu \mathrm{M}$ (GlcNAc, GlcN; AppliChem GmbH, Darmstadt, Germany) and $125 \mu \mathrm{M}$ ([GlcNAc $]_{2}$; Megazyme, Bray, Ireland) and incubated for two days to test the ability of the soil microbial community to metabolize such typical chitin and chitosan hydrolysis products. Hence, the amount of supplemented carbon was higher in chitin and chitosan treatments and corresponded to $400 \mu \mathrm{mol}$, and $360 \mu \mathrm{mol} g_{\text {carbon }}$ soil $_{\text {DW }}^{-1}$, respectively, whereas in the $[\mathrm{GlcNAc}]_{2-}^{-}$, GlcNAc-, and GlcN-supplemented treatments only $8.7 \mu \mathrm{mol}$ and $6.5 \mu \mathrm{mol} g_{\text {carbon }}$ soil $_{\mathrm{DW}}^{-1}$ were added. Concentrations needed to be substantially higher than in situ values in order to stimulate product formation and growth of responding organisms, which would allow for detection by chemical analytics and chiA-TRFLP. Since detection limits of the employed HPLC method was in the range of 30 to $50 \mu \mathrm{M}$ for specific compounds, soluble sugars were employed in equimolar concentrations (based on monomer equivalents) and insoluble biopolymers in higher concentrations. The flasks were incubated in the dark on an end-overend shaker (60 rounds per minute) at $20^{\circ} \mathrm{C}$. Unsupplemented controls were oxic and anoxic soil slurries prepared in the same manner but without supplemented N-sugars. Organic acids, sugars, inorganic anions, and gases were measured as described below. No putative degradation products (e.g., carbon dioxide, organic acids or sugars) were detected in the chitosan treatment within 41 days. Therefore, GC measure- ments were conducted after 156 days to check if chitosan was not degraded or if degradation was hampered.

\subsection{Chemical analytics}

Soil moisture content was determined by weighing sieved (mesh size $2 \mathrm{~mm}$ ) soil before and after drying at $105^{\circ} \mathrm{C}$ for $48 \mathrm{~h}$. Total ammonium, iron, manganese, nitrate, and sulfate concentrations were determined by ion chromatography (Center of Chemical Analytics of Bayreuth Center of Ecological and Environmental Research at the University of Bayreuth, Germany). Ferrous iron was spectrophotometrically measured employing a published method (Tamura et al., 1974). $\mathrm{pH}$ was measured with a $\mathrm{pH}$ meter (U457S7/110 combination pH electrode; Ingold, Germany). Liquid samples (containing soil) and gas samples were taken with sterile syringes. Sampling time points can be retrieved from Figs. 1 and 2, and in the Supplement Fig. S1. Liquid samples were centrifuged at $13000 \mathrm{~g}$ (Himac CT15E, Hitachi Koki Co.,Ltd., Tokyo, Japan) for $15 \mathrm{~min}$ and the supernatant was filtrated (HPLC nylon filter, pore volume $0.2 \mu \mathrm{m}$, Infochroma, Zug, Switzerland). Organic acids and sugars were determined by high-performance liquid chromatography with an ion exclusion column using $4 \mathrm{mM}$ phosphoric acid as eluent (1090 series II with UV detector; Hewlett Packard, Palo Alto, CA) (Wüst et al., 2009). Carbon dioxide, hydrogen gas, and methane were measured with a gas chromatograph (Multigas Analyser SRI 8610C, SRI Instruments, Torrance, CA) equipped with a thermal conductivity detector (TCD) and a helium ionization detector (HID). The injected gas sample was simultaneously separated on two columns. Carbon dioxide and methane were separated on a HayeSep-D column ( $2 \mathrm{~m}$ by $1 / 8$ in.; SRI Instruments, Torrance, CA) coupled to the TCD. Hydrogen gas and methane were separated with a molecular sieve column 13X ( $2 \mathrm{~m}$ by $1 / 8$ in.; Restek, Bellefonte, PA, USA) and detected with the HID. The carrier gas was helium at a flow rate of 40 (TCD) and $20 \mathrm{~mL}$ (HID) $\mathrm{min}^{-1}$, injector and column temperatures were $30^{\circ} \mathrm{C}$ and $60^{\circ} \mathrm{C}$, respectively. Chromatograms were integrated and analyzed with PeakSimple (SRI Instruments, Torrance, CA, USA). Oxygen was measured with a Hewlett Packard Co. (Palo Alto, CA, USA) 5980series II gaschromatograph as previously described (Küsel and Drake, 1995).

\subsection{Extraction of nucleic acids}

Nucleic acids were extracted from $0.4 \mathrm{~g}$ soil slurry using cetyltrimethylammonium bromide (CTAB) and phenolchloroform-isoamyl alcohol $(25: 24: 1)(\mathrm{pH} 8.0)$ based on a published protocol (Griffiths et al., 2000). Liquid samples were taken at $t_{0}$ and $t_{\mathrm{END}}$ from each replicate with sterile syringes and centrifuged at $13000 \mathrm{~g}(1-15 \mathrm{~K}$ Sartorius microcentrifuge, Sigma, Osterode am Harz, Germany) for $15 \mathrm{~min}$. The pelleted soil was used for extraction. Lysis was achieved by bead beating two times at $5.5 \mathrm{~m} \mathrm{~s}^{-1}$ in 


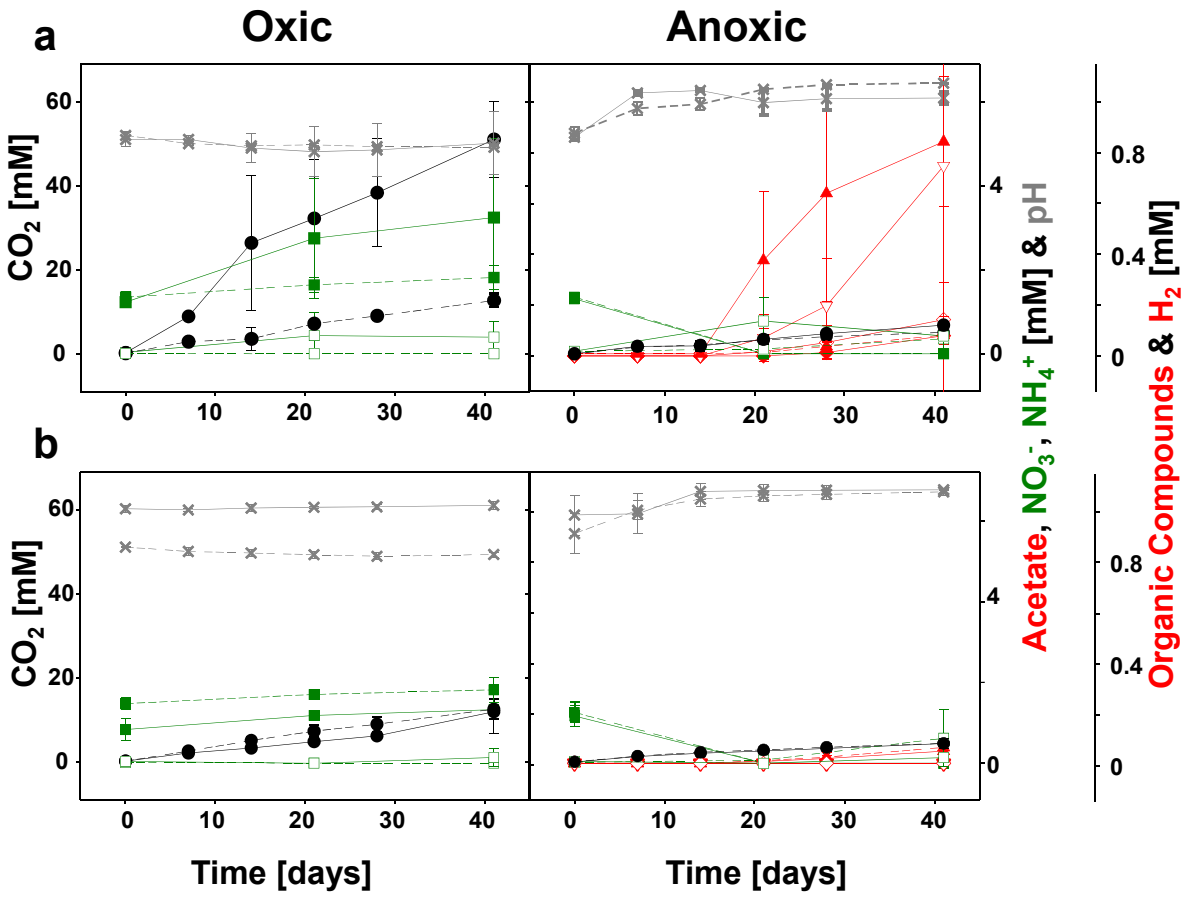

Figure 1. Product formation of soil slurries supplemented with chitin (a) and chitosan (b). Left panels, slurries incubated under oxic atmosphere. Right panels, slurries incubated under oxygen-free atmosphere. Closed black circle, carbon dioxide. Closed green rectangle, nitrate. Open green rectangle, ammonium. Closed red diamond, propionate. Open red diamond, butyrate. Closed red triangle tip up, acetate. Open red triangle tip down, molecular hydrogen. Grey cross, pH. Dashed lines, values of the unsupplemented controls. Error bars, standard deviation replicated soil slurries $(n=3)$. In some cases these errors were so small that they are masked by the symbol.

a bead beater (FastPrep FP 120, Thermo Savant, Holbrook, $\mathrm{NY}$, USA) for $30 \mathrm{~s}$ using zirconium beads $(0.5 \mathrm{~g} \emptyset 0.1 \mathrm{~mm}$, $0.5 \mathrm{~g} \varnothing 0.5 \mathrm{~mm}$; CarlRoth, Karlsruhe, Germany). The following steps were conducted according to the published protocol (Griffiths et al., 2000) and combined RNA and DNA extracts were dissolved in RNAse- and DNAse-free water. RNA was removed by treatment with RNase (Fermentas $\mathrm{GmbH}$, St.Leon-Rot, Germany). DNA was quantified using the Quant-iT ${ }^{\mathrm{TM}}$ PicoGreen ${ }^{\circledR}$ dsDNA kit (Molecular Probes, Eugene, OR, USA) and stored at $-20^{\circ} \mathrm{C}$.

\subsection{TRLFP analysis}

Primer ChiA_F2 was labeled with the infrared dye "Dyomics 681" for terminal restriction fragment length polymorphism (TRFLP) analysis (Microsynth AG, Balgach, Switzerland). The endonucleases MspI, HhaI, HaeIII and AluI were tested in silico with chiA data set retrieved from samples of the conducted slurry incubations (2.6). AluI (data not shown) revealed highest genotype resolution in silico with MEGA version 5 and the REPK Web Tool (Collins and Rocap, 2007; Tamura et al., 2011) and was used for further analyses. Notably, the TRF resolution by MspI was low and yielded many short TRFs below 40bp which are not reliable detectable by the used sequencer (NEN 4300, LI-COR, Lincoln, NE, USA). Therefore, a parallel digestion with $M s p \mathrm{I}$ according to a previous study was omitted (Hjort et al., 2010). Restriction digestion of PCR products was conducted at $37^{\circ} \mathrm{C}$ with $A l u \mathrm{I}$ endonuclease (New England Biolabs $\mathrm{GmbH}$, Frankfurt am Main, Germany) for four hours. Single stranded DNA was removed by digestion with mung bean nuclease (New England Biolabs GmbH, Frankfurt am Main, Germany). Remaining double stranded DNA was quantified with PicoGreen (Quant-iT ${ }^{\mathrm{TM}}$ PicoGreen ${ }^{\circledR}$ dsDNA Kit, Molecular Probes, Eugene, OR, USA), and TRFLP analyses were performed using a NEN4300 LiCOR DNA sequencer as previously described (Hamberger et al., 2008). Gels were analysed using GELQUEST (version 3.1.7, SequentiX GmbH, Klein Raden, Germany). The fluorescence values of TRFs were determined by normalization of the fluorescence value of a detected TRF against the fluorescence value of the respective TRF in the TRFLP profile with the lowest total fluorescence. TRFs with relative frequencies below $3 \%$ were excluded from further analysis as low abundant genotypes are more prone to PCR biases (such as preferential amplification). TRFs were in silico assigned to chiA genotypes (see Sect. 2.6) by searching for the first restriction site in the data set (MEGA, version 5) (Tamura et al., 2011). 

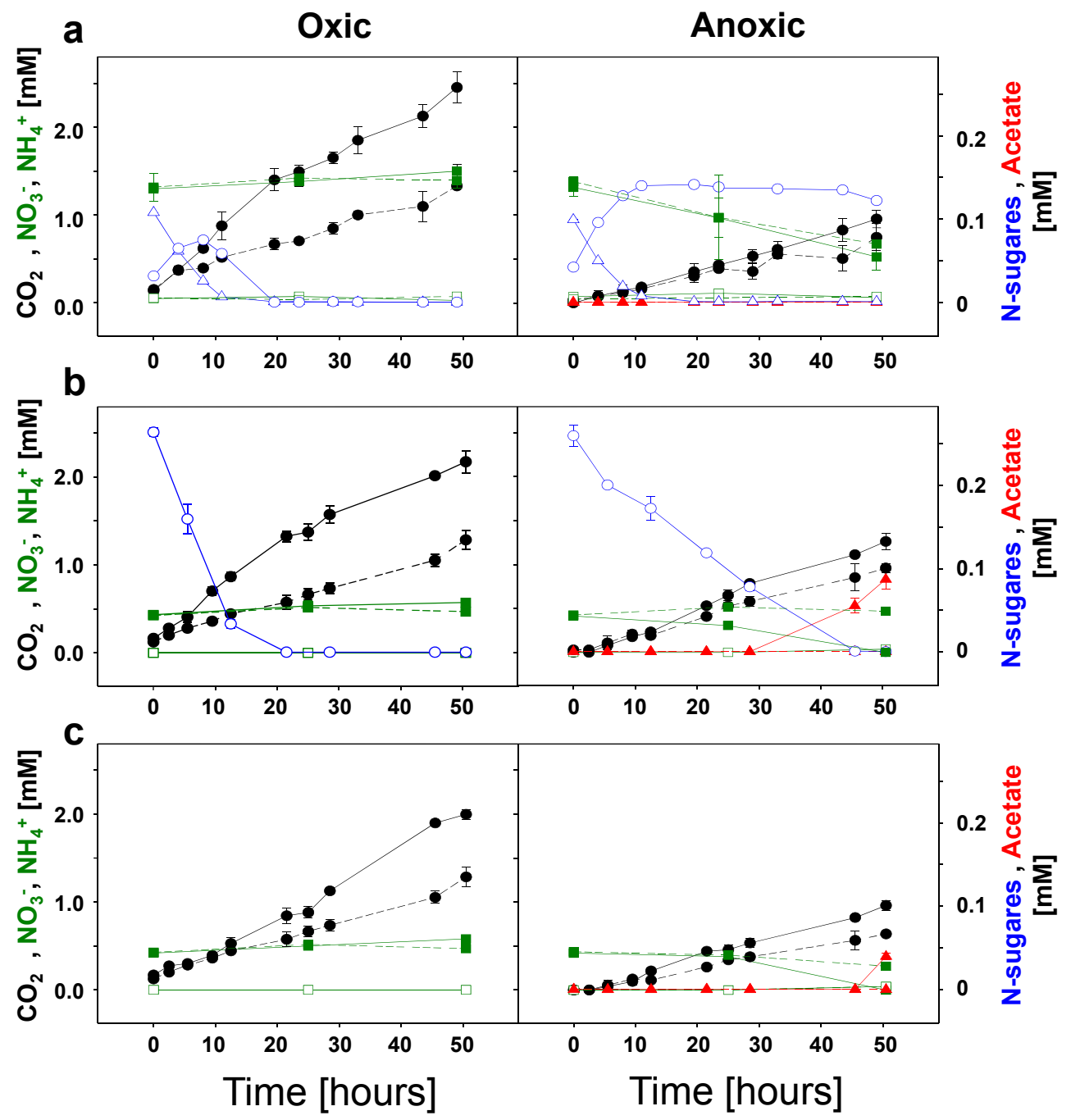

Figure 2. Product formation of soil slurries supplemented with [GlcNAc $]_{2}$ (a), GlcNAc (b), and GlnN (c). Left panels, slurries incubated under oxic atmosphere. Right panels, slurries incubated under oxygen-free atmosphere. Closed black circle, carbon dioxide. Open blue circle, GlcNAc. Open blue triangle tip up, [GlcNAc] 2 . Closed red triangle tip up, acetate. Closed green rectangle, nitrate. Open green rectangle, ammonium. Dashed lines, values of the unsupplemented controls. Error bars, standard deviation of replicated soil slurries $(n=3)$. In some cases these errors were so small that they are masked by the symbol. GlcN was not detectable with the employed HPLC method.

\subsection{Chitinase (chiA) gene libraries}

A fragment of chiA genes was amplified with primers ChiA_F2 (5'-CGT GGA CAT CGA CTG GGA RTW YCC3') and ChiA_R2 (5'-CCC AGG CGC CGT AGA RRT CRT ARS WCA-5') (Hobel et al., 2005). Five chiA libraries were prepared from pooled DNA extracts of $t_{0}$ and $t_{\mathrm{END}}$ samples from each substrate-supplemented treatment. PCR-premix containing Taq-DNA polymerase and all components except for primers and DNA template (MasterMix, 5 PRIME $\mathrm{GmbH}$, Hamburg, Germany) were used for PCR according to previously published protocols (Hobel et al., 2004). End concentrations of primers were $1.0 \mu \mathrm{M}$. In total, 35 cycles were run consisting of a denaturation $\left(45 \mathrm{~s}, 95^{\circ} \mathrm{C}\right)$, an annealing $\left(45 \mathrm{~s}, 42^{\circ} \mathrm{C}\right)$, and an elongation step $\left(90 \mathrm{~s}, 72^{\circ} \mathrm{C}\right)$.
Non-purified PCR products were either (a) commercially cloned and vector inserts were sequenced (LGC Genomics, Berlin, Germany) or (b) cloned into Escherichia coli JM 109 (Promega, Fitchburg, WI, USA) competent cells using the CloneJET PCR Cloning Kit (Thermo Scientific, Erlangen, Germany). Inserted chitinase gene sequences were reamplified using vector specific primers pJET1.2 forward 5'-CGACTCACTATAGGGAGAGCGGC-3' and pJET1.2 reverse 5'-AAGAACATCGATTTTCCATGGCAG-3' and commercially sequenced (Macrogen, Europe). All qualitychecked (i.e., manual removal of chimera, checked identity as being a potential chiA sequences by BLAST Search in nucleotide database of Genbank) chiA sequences (per library between 16 and 67 sequences) were combined in 
one data set, which was used to assign detected TRFs to OTUs and to evaluate the richness of genotypes. Identification of microbial taxa solely by chiA on genus or species level is limited due to obvious incongruences between chiA and organismal phylogenies at these low taxonomic ranks (Karlsson and Stenlid, 2009). Therefore, a threshold value of $50 \%$ amino acid dissimilarity was used to group translated chiA sequences into operational taxonomic units (OTUs) using the software DOTUR (Schloss and Handelsman, 2005). This similarity cut-off threshold refers to the taxonomic rank "class".

\subsection{Phylogenetic analysis of $\operatorname{chiA}$ sequences}

The retrieved data set of partial chiA gene sequences (206 sequences) was edited, translated into amino acid sequences and aligned using CLUSTALW and MUSCLE algorithms in MEGA version 5 (Tamura et al., 2011). The alignments were refined manually. A similarity-based distance matrix was calculated using an alignment of amino acid sequences. Phylogenetic trees were constructed from all sequences, their closest related genotypes (BLAST analysis using the latest version of the GenBank nucleotide database) (Altschul et al., 1990), and distantly related genotypes using MEGA. The chiA tree was calculated using translated amino acid sequences by applying the neighbor-joining algorithm implemented in MEGA 5 (Tamura et al., 2011). Partial deletion with a site coverage cut-off value of $80 \%$ was chosen for gaps and missing data treatment. The topology of the neighbor-joining tree was confirmed with MEGAimplemented maximum likelihood and maximum parsimony algorithms, using the same data set. Tree branches in which reference sequences grouped together with sequences of a single OTU were condensed (Fig. 5).

\subsection{Statistical analyses}

Canonical correspondence analysis (CCA) was conducted to group TRF patterns and to correlate single TRFs with TRF patterns by PAST software package (Hammer et al., 2001). CCA allows to statistically analyze different treatments with not normally distributed data (Schütte et al., 2008). Relative abundances of TRFs were used as variables and correlated with TRF patterns of each treatment replicate (Fig. 4 and Supplement Fig. S5) using the same data as presented in Fig. 3. Presentation option "scaling 2" was chosen to emphasize the relationships between single TRFs and TRF patterns. Selected TRFs were subsequently tested for significant increase from $t_{0}$ to $t_{\mathrm{END}}$ with Mann-Whitney $U$ test (Table S1).

\subsection{Nucleotide sequence accession numbers}

Partial chiA gene sequences of the current study were deposited at EMBL nucleotide database with accession numbers HG315747 to HG315952.

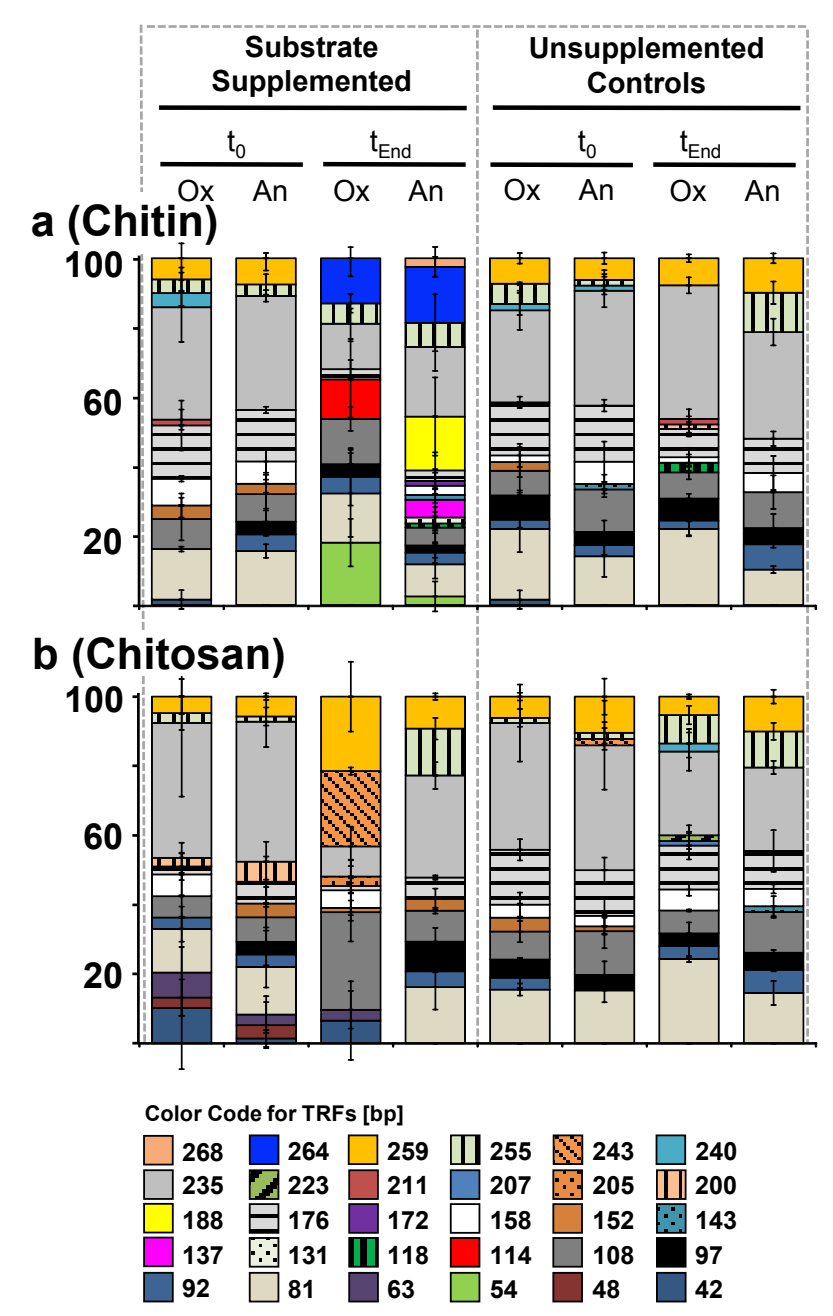

Figure 3. chiA TRFLP patterns of chitin (a) and chitosan (b) supplemented soil slurries. The corresponding process data are presented in Figs. 1 and 2. In each panel the first four bars represent samples from slurries with substrate and the next four samples from a control experiment without substrate supplementation. Within, the order is as follows: $t_{0}$ oxic, $t_{0}$ anoxic, $t_{\mathrm{END}}$ oxic, and $t_{\mathrm{END}}$ anoxic. $t_{\text {END }}$ was at 41 days. Experimental replicates were analysed, i.e., each value of a TRF is based on three DNA extracts $(n=3)$. Errors bars, standard deviation.

\section{Results}

\subsection{Soil properties}

Several soil parameters were determined in freshly collected samples. The $\mathrm{C} / \mathrm{N}$ ratio was $6.9 \pm 0.1$. Soil $\mathrm{pH}$ (measured in water) was $6.6 \pm 0.1$, and the gravimetric water content was $17.7 \%( \pm 0.8 \%)$ and $21.9 \%( \pm 1.0 \%)$ for samplings in 2011 and 2012, respectively. Ammonium, nitrate, and sulfate concentrations were $0.06 \pm 0.15,3.54 \pm 0.14$, and $0.03 \pm 0.14 \mu \mathrm{mol} \mathrm{g} \mathrm{g}_{\text {soilDW }}^{-1}$ in soil samples of 2011 , and $0.42 \pm 0.17,10.50 \pm 2.5$, and $0.17 \pm 0.17 \mu \mathrm{mol} \mathrm{g}_{\text {soildw }}^{-1}$ in 


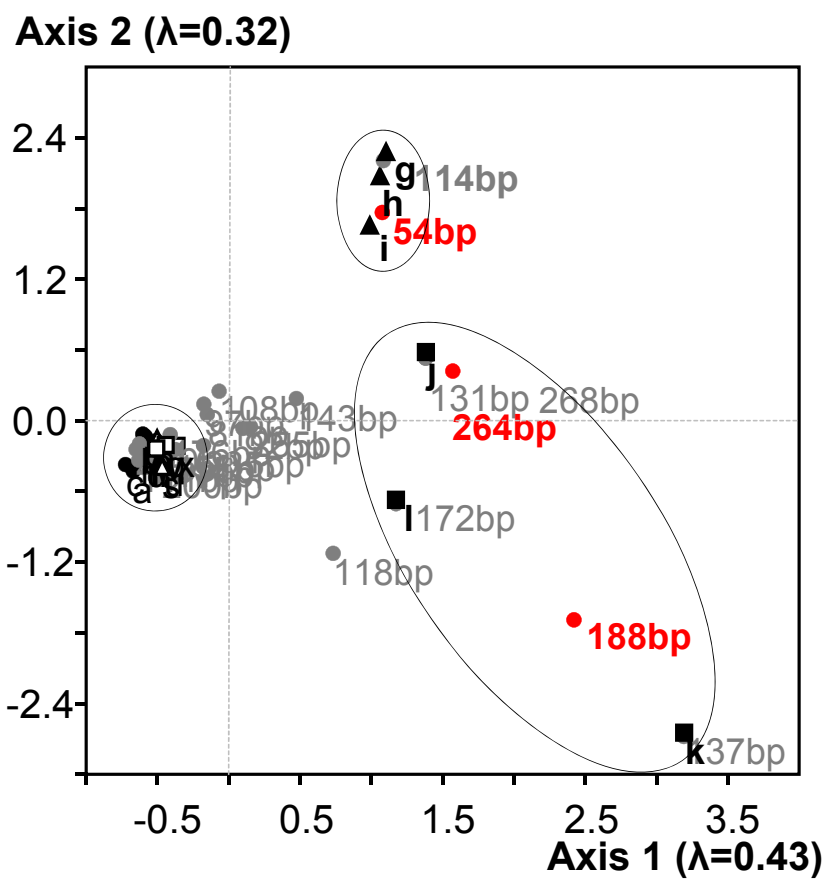

Figure 4. Effect of chitin supplementation on chiA TRF patterns. CCA of TRF patterns of each replicate of the chitin treatment (Fig. 3a). Numbers - TRFs; letters - TRF patterns. TRF patterns of chitin-supplemented treatments: $t_{0}$ oxic $(\mathrm{a}, \mathrm{b}, \mathrm{c}) ; t_{0}$ anoxic $(\mathrm{d}, \mathrm{e}$, $\mathrm{f}) ; t_{\text {END }}$ oxic $(\mathrm{g}, \mathrm{h}, \mathrm{i}) ; t_{\text {END }}$ anoxic $(\mathrm{j}, \mathrm{k}, \mathrm{l})$. TRF patterns of unsupplemented controls: $t_{0}$ oxic $(\mathrm{m}, \mathrm{n}, \mathrm{o}) ; t_{0}$ anoxic $(\mathrm{p}, \mathrm{q}, \mathrm{r}) ; t_{\mathrm{END}}$ oxic $(\mathrm{s}, \mathrm{t}, \mathrm{u}) ; t_{\mathrm{END}}$ anoxic $(\mathrm{v}, \mathrm{w}, \mathrm{x})$. Colored TRFs: significant (Red $p \leq 0.06)$ correlation of TRF with associated TRF patterns as revealed by Mann-Whitney $U$ test (Table S1).

soil samples of 2012. Ferrous iron was not detectable, and total amounts of iron and manganese were $40.0 \pm 15.8$ and $5.3 \pm 3.1 \mu \mathrm{mol} \mathrm{g}$ soilDW, respectively.

\subsection{Effect of oxygen on microbial activities in chitin and chitosan-supplemented agricultural soil slurries}

The effect of supplementation of substrates on the concentration of formed potential products was substantial and exceeded that of unsupplemented controls by at least twofold. Apparent degradation products of chitin were detected under oxic and anoxic conditions within 41 days (Fig. 1a), whereas no effect on microbial product formation was apparent within the same period in chitosan-supplemented slurries (Fig. 1b). Nonetheless, after more than five months carbon dioxide was detected in oxic and anoxic chitosan-supplemented slurries (Fig. S1) suggesting that chitosan degradation was substantially delayed and slower compared with chitin degradation, and that the soil microbial community had only a limited capability to degrade chitosan.

Stimulating effects of chitin supplementation on the microbial product formation were detected after one week under oxic and after three weeks under anoxic conditions sug- gesting slower chitin degradation when oxygen was absent (Fig. 1a). Under oxic conditions, chitin was apparently dissimilated to carbon dioxide (Fig. 1a); $17 \%$ of the presumably degraded nitrogen of chitin was recovered as ammonium and nitrate (data not shown). Oxygen concentration was spot-checked in the course of the experiment and decreased from $21 \%$ to $10 \%$ after 41 days. Under anoxic conditions, measured products were acetate $(5.06 \mathrm{mM})$, propionate $(0.08 \mathrm{mM})$, butyrate $(0.14 \mathrm{mM})$, molecular hydrogen $(0.75 \mathrm{mM})$, and carbon dioxide $(1.7 \mathrm{mM})$, suggesting that various different fermentation metabolisms were active. Ethanol, a typical microbial fermentation product, was not detected. Potential products of chitin hydrolysis ([GlcNAc $]_{2}$ and GlcNAc) were below the detection limit, and thus did not exceed concentrations of $30 \mu \mathrm{M}$. Methane production was not detected, and $\mathrm{pH}$ was stable in oxic treatments at values around 5.2 (chitin) and 6.3 (chitosan), and slightly increased in the anoxic treatments from 5.4 to 6.4 (chitin) and 6.1 to 6.8 (chitosan). End point measurements after 41 days in the anoxic treatments (chitin and chitosan) revealed that high amounts of ferrous iron $(9.7 \pm 0.5 \mathrm{mM})$ were formed.

\subsection{Effect of oxygen on microbial activities in [GIcNAc] 2-, GIcNAc-, and GIcN-supplemented agricultural soil slurries}

The capability of the soil microbial community to metabolize typical chitin and chitosan hydrolysis products was tested by supplementation of [GlcNAc $]_{2}$, GlcNAc, and GlcN to soil slurries. The decrease of [GlcNAc] $]_{2}$ and GlcNAc concentrations was slower in anoxic incubations suggesting a slower uptake and metabolization rates under anoxic conditions (Fig. 2). GlcNAc transiently accumulated in [GlcNAc $]_{2-}$ supplemented slurries indicating that most of the [GlcNAc $]_{2}$ was extracellularly hydrolysed, since GlcNAc was detectable in the liquid phase of the slurries (Fig. 2a). Carbon dioxide was the major product in $[\mathrm{GlcNAc}]_{2}-$ and GlcNAcsupplemented slurries under both oxic and anoxic conditions. Formation of acetate occurred in anoxic GlcNAc- and GlcN-supplemented slurries (Fig. 2b and c). Similar to incubations with chitin, methane production was not detected. $\mathrm{pH}$ was stable in the oxic treatments at values around 5.1 ([GlcNAc $\left.]_{2}\right)$ and 6.1 (GlcNAc, GlcN) and slightly increased in the anoxic treatments from 5.1 to 5.5 ([GlcNAc] $]_{2}$ ) and from 6.1 to 6.4 (GlcNAc, GlcN). Substantial release of ammonium was not observed, whereas detectable nitrate concentrations stayed constant or even decreased over time in both oxic and anoxic treatments. These observations suggested that within the short incubation period no substantial net production of inorganic nitrogen compounds (as observed in the long-term incubation with chitin Fig. 1a) occurred. GlcN stimulated microbial activity under both oxic and anoxic conditions. However, product formation was delayed compared to slurries that were supplemented with [GlcNAc $]_{2}$ and GlcNAc (Fig. 2). 


\section{4 chiA TRFs responding to chitin supplementation}

The response of chiA genotypes to the supplementation of chitin, chitosan, [GlcNAc $]_{2}$, GlcNAc, and GlcN was evaluated by TRFLP analysis (Figs. 3 and S4). DNA extracts from each replicate of a treatment were analyzed to assess the variability of genotype diversity in the soil slurries and further analyzed by CCA and Mann-Whitney $U$ test to identify changed TRFs (Figs. 4, S5 and Table S1).

An effect of substrate supplementation and/or oxygen availability on chiA TRF patterns was not evident for $[\mathrm{GlcNA}]_{2-}$, GlcNAc-, and GlcN-supplemented slurries. Likely, the short time period (2 days) did not allow for substantial growth, and thus there were no detectable changes in TRF patterns (Figs. S4 and S5). In the chitosansupplemented slurries, $t_{\text {END }}$ patterns under oxic conditions were separated according to CCA plots from $t_{0}$ TRF patterns and the $t_{\text {END }}$ unsupplemented controls (Figs. 3b and S5a). A change due to chitosan degradation was not likely, since potential degradation products were not detected at that time point (Fig. 1b), whereas after 156 days a net increase of carbon dioxide was observed in both oxic and anoxic treatments (Fig. S1) suggesting a strongly delayed degradation of chitosan.

Several TRFs responded positive towards chitin supplementation and led to a shift in the TRF patterns (Figs. 3a and 4$). t_{\text {END }}$ TRF patterns of chitin-supplemented slurries were different from $t_{0}$ patterns and the respective unsupplemented controls at $t_{\text {END }}$ under both oxic and anoxic conditions (Fig. 4a). Thereby, the TRF patterns under anoxic condition exhibited a larger variability. Under oxic conditions, TRFs $114 \mathrm{bp}$ and 54bp positively responded and correlated with the shift of TRF patterns (Fig. 4), whereby TRF 54bp had the bigger influence. Under anoxic conditions TRFs $137 \mathrm{bp}$ and $188 \mathrm{bp}$ responded positively and were responsible for the shift. TRF 264bp was detected under oxic and anoxic conditions (Figs. 3a and 4) and correlated with the shift of the patterns under oxic and anoxic conditions. TRFs $114 \mathrm{bp}, 188 \mathrm{bp}$, and 264bp significantly increased their relative abundance (Table S1). The response of TRF 114bp was less significant $(p \leq 0.20)$ and was found in only two of three replicates (relative abundance 10.7[ \pm 10.2$] \%$ ). TRF $137 \mathrm{bp}$ influenced the pattern for one replicate (k, Fig. 4) under anoxic conditions due to its high relative abundance $(14.6 \%)$ but the increase of its relative abundance was not significant ( $p \leq 0.51$, Figs. 4 and Table S1).

\subsection{Diversity of $\operatorname{chiA}$-like genotypes}

In total, 206 chiA-like genotypes were detected and grouped into 42 OTUs (Figs. 5, S2, and S3). Based on the cut-off value (similarity $\geq 50 \%$ ), rarefaction analysis revealed sufficient sampling depth, although a plateau indicative of a complete coverage of genotype diversity was not fully reached (Fig. S2). The high number of detected OTUs suggested a large chiA genotype richness in the microbial community of the investigated agricultural soil. Twenty-two OTUs affiliated with $c h i A$-genotypes of cultivated species (similarity $\geq 60 \%$ ), and were assigned to Beta- and Gammaproteobacteria (OTU 2, 12, 19), Actinobacteria (OTU 7 and 20), Acidobacteria (OTU 4 and 26), Bacteriodetes (OTU 9, 14, and 28), Firmicutes (OTU 10 and 15), Planctomycetes (OTU 1), Chloroflexi (OTU 11), and microeukaryotes (OTU 17, 21, 24, 25, 41, 27, and 37) (Fig. 5); on the other hand, OTUs $3,5,6,8,13,16,18,22,23,29-36$, and 38-42 represented novel chiA genotypes based on their high dissimilarity to known chiA genotypes (dissimilarity $>40 \%$ ) and their separate branching (Figs. 5 and S3).

Eukaryote-like chiA sequences accounted for a minor fraction of detected chiA OTUs and were closest related to those of either fungi (Basidiomycota; OTU 17, 25 and 41), Amoebozoa (OTU 24), or diatoms (Heterokontophyta, OTUs 21 and 27) (Figs. 5 and S3). Basidomycota are known to be comprised of chitinolytic species (Gooday, 1990a, b; Tracey, 1955). Bacteria might have outcompeted chitinolytic Basidiomycota in soil slurries based on data of the current study (Figs. 3a, 4 and 5). Nonetheless, it should be noted that used primers were developed for targeting bacterial chiAsequences, and thus conclusions with regard to eukaryotic genotypes are limited.

\section{Discussion}

\subsection{Microbial response to chitin and chitosan supplementation in agricultural soil slurries}

Degradation of chitin and chitosan flakes was slow in a previous field experiment and detectable degradation and a substantial loss of flakes mass was observed after 50 and 180 days, respectively (Sato et al., 2010). In the current study, stimulation of microbial activity in chitosan-supplemented slurries was substantially delayed compared to the rapid stimulation by chitin under both oxic and anoxic conditions (Figs. 1 and S1). The faster response to chitin as compared to the response times of the study by Sato el al. (2010) can be explained by a higher physical accessibility of the used biopolymers in the current study (since ground chitin was used) and by an unknown effect of the divergent incubation conditions employed in both studies. The response of chiA genotypes on and the rapid stimulation of microbial activity in supplemented agricultural soil slurries suggested that the soil microbial community was better adapted to chitin as substrate than to chitosan. This observation was in agreement with our expectations, as chitin is more abundant than chitosan in nature. For example, with few exceptions chitin occurs ubiquitously in fungi, whereas chitosan is only found in Zygomycetes (Gooday, 1990a; Raafat et al., 2008) suggesting that microbial communities were more prone to degrade chitin than chitosan in soil. In agreement with this 


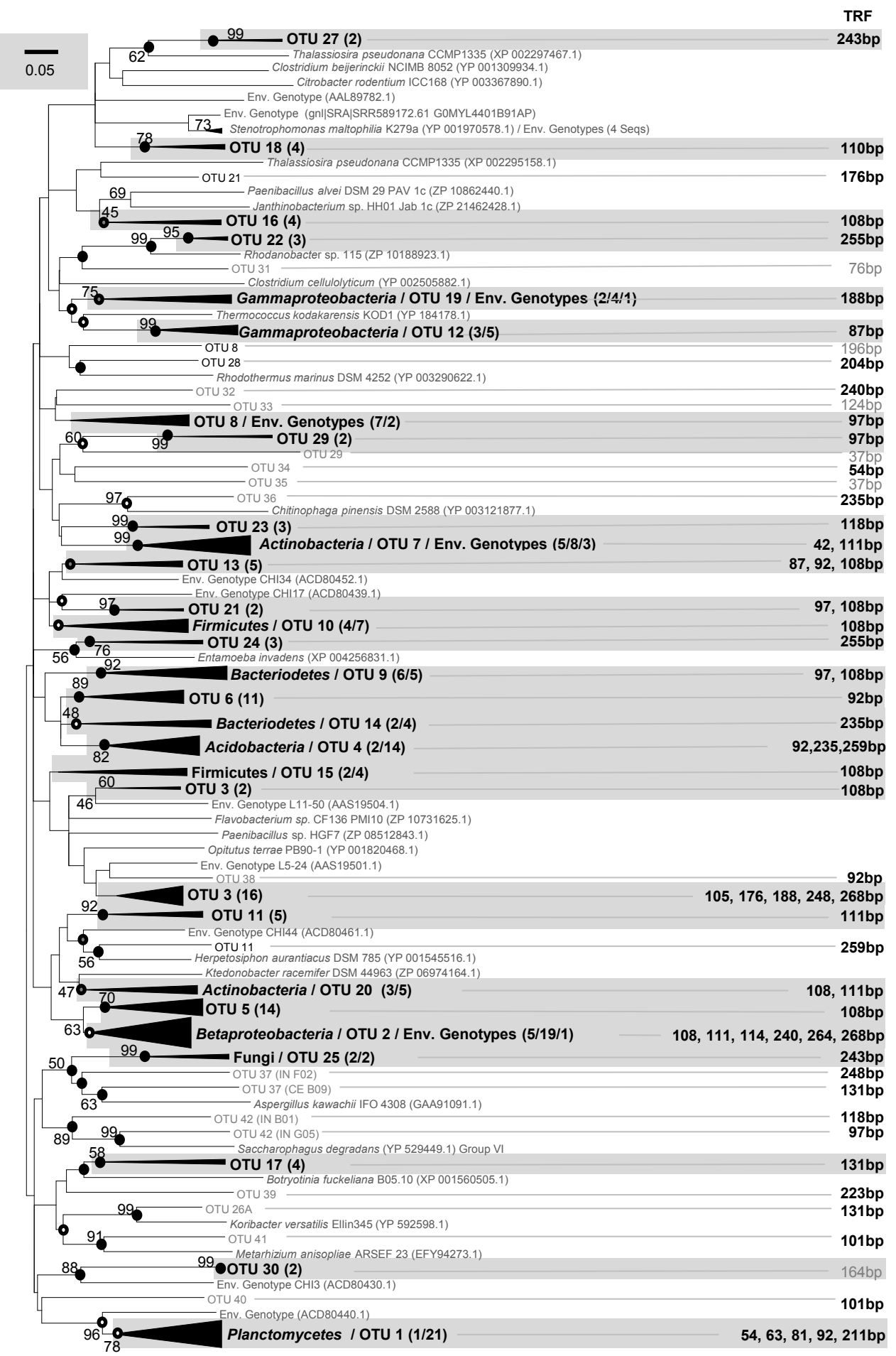

Figure 5. Phylogenetic tree of chiA OTUs (206 sequences) and references (78 sequences). The expanded tree is presented in Fig. S3. chiA gene libraries were prepared from pooled DNA extracts of each substrate treatment and data were combined for the figure. Gray numbers in parentheses, accession numbers of reference sequences. For condensed branches OTUs and taxonomic affiliation of reference sequences are indicated in bold letters and the numbers of reference sequences, OTU sequences and environmental sequences are given in parentheses. Accession numbers for reference sequences of the condensed branches can be found in Fig. S3. Numbers on the right side, TRFs corresponding to genotypes identified by in silico analysis. The tree was calculated using translated amino acid sequences with neighborjoining algorithm (MEGA 5; Tamura et al., 2011) including bootstrapping (1000 replicates; percentage values at nodes). Open circles and gray filled circles at nodes, these nodes were confirmed by maximum likelihood and maximum parsimony algorithms, respectively, using the same data set. Black circles, confirmation by both algorithms. Scale bar, $5 \%$ sequence divergence. 
hypothesis, product formation in GlcN-supplemented slurries (i.e., a potential product of chitosan hydrolysis) was delayed compared with slurries that were supplemented with potential products of chitin hydrolysis, that is, $[\mathrm{GlcNAc}]_{2}$ and GlcNAc (Fig. 2). The relevance of deacetylation and subsequent chitosan hydrolysis for soil communities has not experimentally been addressed in previous studies. Our experimental data suggest that chitin was largely not deacetylated, and that it is likely that hydrolysis without prior deacetylation was the preferential pathway of chitin breakdown of the investigated soil microbial community.

\subsection{Effect of oxygen on community metabolism in chitin supplemented treatments}

Chitin stimulated microbial activity without apparent delay under oxic conditions with carbon dioxide being the sole detected carbonaceous product. Stimulation of the microbial activity under anaerobic conditions was evident after three weeks (Fig. 1b) suggesting a slower degradation compared to aerobic degradation. Potential products of chitin hydrolysis ([GlcNAc $]_{2}$ and GlcNAc) could not be detected suggesting an efficient consumption of hydrolysis products leading to low steady state concentrations (i.e., $<30 \mu \mathrm{M}$ ). The generally lower degradation rate of $\mathrm{N}$-sugars under anoxic conditions likely explains the lower rate of apparent chitin degradation under anoxic conditions.

Detected anaerobic products were indicative for mixed acid and butyric acid fermentation (Buckel, 2005; White, 2007). Propionate and butyrate were not detected in the short-term experiments with [GlcNAc $]_{2}$, GlcNAc, and GlcN suggesting that these products were intermediates in the sequence of products of anaerobic microbial degradation of chitin, which became detectable when the sequential reactions became decoupled due to high substrate input. Acetate production might have been additionally associated with syntrophic fermentation and acetogenesis (Wagner et al., 1996; Drake et al., 2009). The same degradation products were detected under anoxic conditions when cellulose was supplemented to soil slurries in the same soil (Schellenberger et al., 2010). Ferrous iron formation in the anoxic chitin and chitosan treatments suggested that ferric iron reducers consumed a part of fermentation products, which was also found with anaerobic cellulose degradation in the same soil (Schellenberger et al., 2010). Nitrate formation in the oxic treatments supplemented with chitin was likely caused by nitrification of released ammonium (Schulten and Schnitzer, 1998; Kowalchuk and Stephen, 2001; Erguder et al., 2009) and nitrate consumption in the anoxic treatments due to dissimilatory nitrate reduction (Kraft et al., 2011). The C/N ratio as well as the high initial nitrate concentrations (Figs. 1 and 2) indicate that nitrogen was not limiting for microbial metabolism in the investigated agricultural soil. This likely explains why nitrogen from chitin was not fully utilized, and $17 \%$ were recovered as ammonium and nitrate in the oxic treatments. Anaerobic degradation products of chitin and Nsugars were largely similar to that of anaerobic cellulose degradation of the same soil, that is, the only divergent observation was net release of ammonium from chitin through ammonification.

\subsection{Responding chiA genotypes and diversity in chitin supplemented slurries}

A broad diversity of chiA genotypes (Figs. 5 and S3) indicative of organisms that have the potential to hydrolyze chitin was detected. However, few of the detected chiA genotypes were stimulated by chitin supplementation under experimental conditions.

chiA TRFs that were stimulated by chitin supplementation were affiliated with Betaproteobacteria (OTU 2; TRFs 114bp and 264bp), Gammaproteobacteria (OTU 19; TRF 188bp), Planctomycetes (OTU 1, 34; TRF 54bp), and a novel chiA genotype (OTU 3; TRF 188bp). TRFs 114bp and 54bp that were detected in oxic treatments likely represented aerobic microorganisms, whereas TRF 188bp represented anaerobic and facultative aerobic microorganisms. TRF 264bp that was detected under both oxygen conditions was indicative of facultative aerobic chitinolytic microorganisms. OTU 3 represented a chiA genotype of yet unidentified microorganisms that were active under anoxic conditions. Most similar sequences (5-44\% amino acid sequence dissimilarity) and already known genotypes were two environmental sequences from Antarctic lake sediments (L5-24, L11-50), which were most closely related with bacterial chiA genes (Figs. 5 and S3). Thus, OTU 3 likely represented previously unknown anaerobic chitinolytic Bacteria.

OTU 1 positively responded under oxic conditions and affiliated with Singulisphaera acidiphila. chiA has been detected in the genome of $S$. acidiphila suggesting that $S$. acidiphila might hydrolyze chitin (Kulichevskaya et al., 2008; Guo et al., 2012). However, Planctomycetes have not been shown to be chitinolytic to date (Ivanova and Dedysh, 2012). Planctomycetes (including Singulisphaera acidiphila) are able to utilize GlcNAc as sole carbon and energy source (Schlesner, 1994; Fuerst et al., 1997; Rabus et al., 2002). Therefore, the physiological function of the chiA gene in $S$. acidiphila needs to be considered as elusive based on current knowledge of substrate spectra of Planctomycetes isolates. Nonetheless, our study suggests that Planctomycetes were somewhat involved in chitin degradation. A possible role of Planctomycetes in the degradation of biopolymers such as chitin and cellulose is in agreement with the detection of a ${ }^{13} \mathrm{C}$ labelled ribosomal RNA of Planctomycetes in ${ }^{13} \mathrm{C}$ cellulose-supplemented oxic soil slurries of the same agricultural soil (Schellenberger et al., 2010).

Beta- and Gammaproteobacteria-like genotypes were abundant genotypes in the chiA data set, and members of these groups were stimulated by chitin supplementation under both oxic and anoxic conditions (Figs. 3 and 4). 
Supplementation of chitin to agricultural soil slurries also stimulated a rapid response of Beta- and Gammaproteobacteria (Kielak et al., 2013), whereas a previous field study revealed that chitin supplementation positively correlated with increased abundances of Actinobacteria and Oxalobacteracea (Betaproteobacteria) (Cretoiu et al., 2013). Thus, experimental conditions (for example soil slurries vs. field conditions) obviously affect the activity of certain chitinolytic taxa.

Responding Betaproteoabacteria-like chiA genotypes of the current study had high similarities (66\% to $94 \%)$ with chiA sequences of two species of Oxalobacteracea (Janthinobacterium lividum PAMC 25724 [ZP 10443966.1], Janthinobacterium sp. HH01 Jab 2c [ZP 21465866.1]) (Fig. S3). Oxalobacteracea (Betaproteobacteria) therefore likely play a crucial role in the degradation of chitin in agricultural soils.

Various chiA TRFs positively responded to chitosan supplementation under oxic not under anoxic conditions (Fig. S4a). Stimulation of net product formation did not occur (Fig. 1b). Carbon dioxide production was equal in chitosan-supplemented treatments and unsupplemented controls (Fig. 1b). Thus, the stimulation of TRFs was likely not caused by microbial utilization of chitosan. Chitosan might have functioned as substrate analog that triggered growth of certain chiA harboring organisms, which utilized nonpolymeric substrates and outcompeted those that were active in the absence of chitosan. Although further experiments are required to resolve this issue, lacking net formation of carbon dioxide or any other product suggested that the investigated community was not prone to utilize chitosan.

Notably, most of the detected genotypes did not respond, which included beyond Actinobacteria, other well-known chitinolytic soil bacteria, such as Clostridia. The lack of response does not necessarily mean that the associated taxa were not actively involved in chitin degradation. They might have been active, but did not substantially grow.

\subsection{Non-responding $\operatorname{chiA}$ genotypes}

A high fraction (48\%) of chiA genotypes that did not respond to substrate supplementation were novel, i.e., they were only distantly related ( $\leq 60 \%$ protein sequence similarity) to known genotypes and chiA genes of cultivated taxa. Thus, it remains speculative which organisms were represented by those genotypes. $52 \%$ of the not-responding chiA genotypes affiliated with Actinobacteria, Bacteriodetes, Gammaproteobacteria, Firmicutes, Acidobacteria, Chloroflexi, and eukaryotes.

Bacteriodetes, Firmicutes, and Actinobacteria are known to comprise chitinolytic members, whereby Actinobacteria are often regarded as the most important chitin degraders in aerated soils (Gooday, 1990a, b; Williamson et al., 2000; Krsek and Wellington, 2001; Metcalfe et al., 2002). Thus, the apparent lack of response of Actinobacteria was unexpected and might be related to the experimental conditions (soil slurries, i.e., liquid phase and permanent shaking) of this study. It has been suggested that in freshwater environments planktonic Actinobacteria rather rely on the uptake of chitin hydrolysis products without expressing chitinases than hydrolyzing the substrate themselves (Beier et al., 2011a). Whether this "cheater" acquisition strategy could explain the lack of response in the current study needs to be evaluated.

In contrast to aforementioned phyla, chitinolytic lifestyle has not been well established in Acidobacteria, which are abundant in soils and difficult to cultivate (Janssen, 2006). Recently, the first chitinolytic strain (Blastocatella fastidiosa) was isolated (Foesel et al., 2013). Further evidence that chitinolysis is a trait of Acidobacteria was revealed by comparative genome analyses of three acidobacterial strains (Ward et al., 2009). The chiA-like genes that were detected in the current study were possibly functional chitinases of novel chitinolytic Acidobacteria. Future studies are warranted to verify the capability of the chitinolytic lifestyle in this bacterial phylum.

\section{Final conclusions}

The investigated soil microbial community likely degraded chitin via "direct" hydrolysis and not by initial deacetylation to chitosan under experimental conditions. Detection of OTU 3 and further deep-branching OTUs suggested as well that hitherto unknown chitinolytic microorgansims occurred in our soil. Betaproteobacterial and a novel Planctomycetes-like chiA genotypes were stimulated by supplemental chitin under oxic and Beta-, Gammaproteobacterial, and novel (OTU 3) chiA genotypes under anoxic conditions. Thus, detected chitinolytic bacteria occupied different ecological niches with regard to oxygen availability. In the same soil, also cellulolytic bacteria differentially responded to oxygen availability (Schellenberger et al., 2010, 2011). Thus, aforementioned findings provide evidences that support the hypothesis that the highly variable catabolic diversity of biopolymer degrading microbes enables continued biopolymer degradation despite fluctuations of oxygen concentration in soil.

\section{The Supplement related to this article is available online at doi:10.5194/bg-11-3339-2014-supplement.}


Acknowledgements. The authors thank Michael Schloter for providing soil samples, Florian Just for technical assistance, Matthias Noll for supervision of statistics and Harold L. Drake for general support of the study. This study was funded by a project grant of the Deutsche Forschungsgemeinschaft (DFG; Ko2912/3-2), which is a part of the DFG Priority Program "Biogeochemical Interfaces in Soils" SPP1315.

Edited by: K. Küsel

\section{References}

Altschul, S. F., Gish, W., Miller, W., Myers, E. W., and Lipman, D. J.: Basic local alignment search tool, J. Mol. Biol., 215, 403-410, 1990.

Arimori, T., Kawamoto, N., Okazaki, N., Nakazawa, M., Miyatake, K., Shinya, S., Fukamizo, T., Ueda, M., and Tamada, T.: Crystal structures of the catalytic domain of a novel glycohydrolase family 23 chitinase from Ralstonia sp. A-471 reveals a unique arrangement of the catalytic residues for inverting chitin hydrolysis, J. Biol. Chem., 288, 18696-18706, 2013.

Beier, S. and Bertilsson, S.: Uncoupling of chitinase activity and uptake of hydrolysis products in freshwater bacterioplankton, Limnol. Oceanogr., 56, 1179-1188, 2011a.

Beier, S., Jones, C. M., Mohit, V., Hallin, S., and Bertilsson, S.: Global phylogeography of chitinase genes in aquatic metagenomes, Appl. Environ. Microb., 77, 1101-1106, $2011 \mathrm{~b}$.

Beier, S. and Bertilsson, S.: Bacterial chitin degradation - mechanisms and ecophysiological strategies, Front. Microbiol., 4, 149, doi:10.3389/fmicb.2013.00149, 2013.

Buckel, W.: Special clostridial enzymes and fermentation pathways, in: Handbook on Clostridia, edited by: Dürre, P., CRC Press, Boca Raton, FL, USA, 177-220, 2005.

Cantarel, B. L., Coutinho, P. M., Rancurel, C., Bernard, T., Lombard, V., and Henrissat, B.: The Carbohydrate-Active EnZymes database (CAZy): an expert resource for glycogenomics, Nucleic Acids Res., 37, 233-238, 2009.

Cohen-Kupiec, R. and Chet, I.: The molecular biology of chitin digestion, Curr. Opin. Biotech., 9, 270-277, 1998.

Collins, R. E. and Rocap, G.: REPK: an analytical web server to select restriction endonucleases for terminal restriction fragment length polymorphism analysis, Nuc. Acids Res, 35, 58-62, doi:10.1093/nar/gkm384, 2007.

Cottrell, M. T., Moore, J. A., and Kirchman, D. L.: Chitinases from uncultured marine microorganisms, Appl. Environ. Microb., 65, 2553-2557, 1999.

Cretoiu, M. S., Kielak, A. M., Abu Al-Soud, W., Sørensen, S. J., and van Elsas, J. D.: Mining of unexplored habitats for novel chitinases - chiA as a helper gene proxy in metagenomics, Appl. Microbiol. Biot., 94, 1347-1358, 2012.

Cretoiu, M. S., Korthals, G. W., Visser, J. H.M, and van Elsas, J. D.: Chitin amendment increases soil suppressiveness toward plant pathogens and modulates the actinobacterial and oxalobacteraceal communities in an experimental agricultural field, Appl. Environ. Microb., 79, 5291-5301, 2013.

Drake, H. L., Horn, M. A., and Wüst, P. K.: Intermediary ecosystem metabolism as a main driver of methanogenesis in acidic wetland soil, Environ. Microbiol. Reports, 1, 307-318, 2009.
Erguder, T. H., Boon, N., Wittebolle, L., Marzorati, M., and Verstraete, W.: Environmental factors shaping the ecological niches of ammonia oxidizing archaea, FEMS Microbiol. Rev., 33, 855869, 2009.

Foesel, B. U., Rohde, M., and Overmann, J.: Blastocatella fastidiosa gen. nov., sp. nov., isolated from semiarid savanna soil the first described species of Acidobacteria subdivision 4, Syst. Appl. Microbiol., 36, 82-89, 2013.

Fuerst, J. A., Gwilliam, H. G., Lindsay, M., Lichanska, A., Belcher, C., Vickers, J. E., and Hugenholtz, P.: Isolation and molecular identification of planctomycete bacteria from postlarvae of the giant tiger prawn, Penaeus monodon, Appl. Environ. Microb., 63, 254-262, 1997.

Fujita, K., Shimomura, K., Yamamoto, K., Yamashita, T., and Suzuki, K.: A chitinase structurally related to the glycoside hydrolase family 48 is indispensable for the hormonally induced diapause termination in a beetle, Biochem. Bioph. Res. Co., 345, 502-507, 2006.

Fuka, M. M., Engel, M., Gattinger, A., Bausenwein, U., Sommer, M., Munch, J. C., and Schloter, M.: Factors influencing variability of proteolytic genes and activities in arable soils, Soil Biol. Biochem., 40, 1646-1653, 2008.

Geisseler, D., Horwath, W. R., Joergensen, R. G., and Ludwig, B.: Pathways of nitrogen utilization by soil microorganisms - a review, Soil Biol. Biochem., 42, 2058-2067, 2010.

Gooday, G. W.: The ecology of chitin degradation, Adv. Microb. Ecol., 11, 387-430, 1990a.

Gooday, G. W.: Physiology of microbial degradation of chitin and chitosan, Biodegradation, 1, 177-190, 1990b.

Griffiths, R. I., Whiteley, A. S., O'Donnell, A. G., and Bailey, M. J.: Rapid method for coextraction of DNA and RNA from natural environments for analysis of ribosomal DNA- and rRNA- based microbial community composition, Appl. Environ. Microb., 66, 5488-5491, 2000.

Guo, M., Han, X., Jin, T., Zhou, L., Yang, J., Li, Z., Chen, J., Geng, B., Zou, Y., Wan, D., Li, D., Dai, W., Wang, H., Chen, Y., Ni, P., Fang, C., and Yang, R.: Genome sequences of three species in the family Planctomycetaceae, J. Bacteriol., 194, 3740-3741, 2012.

Hamberger, A., Horn, M. A., Dumont, M. G., Murrell, J. C., and Drake, H. L.: Anaerobic consumers of monosaccharides in a moderately acidic fen, Appl. Environ. Microb., 74, 3112-3120, 2008.

Hammer, Ø., Harper, D. A. T., and Ryan, P. D.: PAST: paleontological statistics software package for education and data analysis, Palaeontol. Electron., 4, 4, 2001.

Henrissat, B. and Bairoch, A.: New families in the classification of glycosyl hydrolases based on amino acid sequence similarities, Biochem. J., 293, 781-788, 1993.

Hillman, K., Gooday, G. W., and Prosser, J. I.: The mineralization of chitin in the sediments of the Ythan Estuary, Aberdeenshire, Scotland, Estuar. Coast. Shelf S., 29, 601-612, 1989a.

Hillman, K., Gooday, G. W., and Prosser, J. I.: A simple model system for small scale in vitro study of estuarine sediment ecosystems, Lett. Appl. Microbiol., 4, 41-44, 1989b.

Hjort, K., Bergström, M., Adesina, M. F., Jansson, J. K., Smalla, K., and Sjöling, S.: Chitinase genes revealed and compared in bacterial isolates, DNA extracts and a metagenomic library from 
a phytopathogen-suppressive soil, FEMS Microbiol. Ecol., 71, 197-207, 2010.

Hobel, C. F. V., Marteinsson, V. T., Hauksdottir, S., Fridjonsson, O. H., Skirnisdottir, S., Hreggvidsson, G. O., and Kristjánsson, J. K.: Use of low nutrient enrichments to access novel amylase genes in silent diversity of thermophiles, World J. Microb. Biot., 20, 801-809, 2004.

Hobel, C. F. V., Marteinsson, V. T., Hreggvidsson, G. O., and Kristjánsson, J. K.: Investigation of the microbial ecology of intertidal hot springs by using diversity analysis of $16 \mathrm{~S}$ rRNA and chitinase genes, Appl. Environ. Microb., 71, 2771-2776, 2005.

Ikeda, S., Ytow, N., Ezura, H., Minamisawa, K., Miyashita, K., and Fujimura, T.: Analysis of molecular diversity of bacterial chitinase genes in the maize rhizosphere using culture-independent methods, Microbes Environ., 22, 71-77, 2007.

Ivanova, A. O. and Dedysh, S. N.: Abundance, diversity, and depth distribution of Planctomycetes in acidic northern wetlands, Front. Microbiol., 3, 5, doi:10.3389/fmicb.2012.00005, 2012.

Janssen, P. H.: Identifying the dominant soil bacterial taxa in libraries of $16 \mathrm{~S}$ rRNA and 16S rRNA genes, Appl. Environ. Microb., 72, 1719-1728, 2006.

Karlsson, M. and Stenlid, J.: Evolution of family 18 glycoside hydrolases: diversity, domain structures and phylogenetic relationships, J. Mol. Microb. Biotech., 16, 208-223, 2009.

Kasprzewska, A.: Plant chitinases - Regulation and function, Cell Mol. Biol. Lett., 8, 809-824, 2003.

Kellner, H. and Vandenbol, M.: Fungi unearthed: Transcripts encoding lignocellulolytic and chitinolytic enzymes in forest soil, PLoS ONE, 5, e10971, doi:10.1371/journal.pone.0010971, 2010.

Keyhani, N. O. and Roseman, S.: Physiological aspects of chitin catabolism in marine bacteria, Biochim. Biophys. Acta, 1473, 108-122, 1999.

Kielak, A. M., Cretoiu, M. S., Semenov, A. V., Sørensen, S. J., and van Elsas, J. D.: Bacterial chitinolytic communities respond to chitin and $\mathrm{pH}$ alteration in soil, Appl. Environ. Microb., 79, 263 272, 2013

Köllner, K. E., Carstens, D., Keller, E., Vazquez, F., Schubert, C. J., Zeyer, J., and Bürgmann, H.: Bacterial chitin hydrolysis in two lakes with contrasting trophic statuses, Appl. Environ. Microb., 78, 695-704, 2012.

Kowalchuk, G. A. and Stephen, J. R.: Ammonia-oxidizing bacteria: a model for molecular microbial ecology, Annu. Rev. Microbiol., 55, 485-529, 2001.

Kulichevskaya, I. S., Ivanova, A. O., Baulina, O. I., Bodelier, P. L. E., Damste, J. S. S., and Dedysh, S. N.: Singulisphaera acidiphila gen. nov., sp. nov., a non-filamentous, Isosphaera-like Planctomycete from acidic northern wetlands, Int. J. Syst. Evol. Micr., 58, 1186-1193, 2008.

Küsel, K. and Drake, H. L.: Effects of environmental parameters on the formation and turnover of acetate by forest soils, Appl. Environ. Microb., 61, 3667-3675, 1995.

Kraft, B., Strous, M., and Tegetmeyer, H. E.: Microbial nitrate respiration - genes, enzymes and environmental distribution, J. Biotechnol., 155, 104-117, 2011.

Krsek, M. and Wellington, E. M. H.: Assessment of chitin decomposer diversity within an upland grassland, Anton. Leeuw. Int. J. G., 79, 261-267, 2001.
LeCleir, G. R., Buchan, A., and Hollibaugh, J. T.: Chitinase gene sequences retrieved from diverse aquatic habitats reveal environment-specific distributions, Appl. Environ. Microb., 70, 6977-6983, 2004.

LeCleir, G. R., Buchan, A., Maurer, J., Moran, M. A., and Hollibaugh, J. T.: Comparison of chitinolytic enzymes from an alkaline, hypersaline lake, and an estuary, Environ. Microbiol., 9, 197-205, 2007.

Manucharova, N. A., Yaroslavtsev, A. M., Senchenko, D. V., Stepanov, A. L., and Zvyagintsev, D. G.: Microbial transformation of chitin in soil under anaerobic conditions, Biol. Bull., 33 191-194, 2006.

Manucharova, N. A., Vlasenko, A. N., Men'ko, E. V., and Zvyagintsev, D. G.: Specificity of the chitinolytic microbial complex of soils incubated at different temperatures, Microbiology, 80, 205215, 2011.

Martínez, J. P., Falomir, M. P., and Gozalbo, D.: Chitin: A structural biopolysaccharide, in: Encyclopedia of Life Sciences (ELS), John Wiley \& Sons, Ltd, Chichester, doi:10.1002/9780470015902.a0000694.pub2, 2009.

Metcalfe, A. C., Krsek, M., Gooday, G. W., Prosser, J. I., and Wellington, E. M. H.: Molecular analysis of a bacterial chitinolytic community in an upland pasture, Appl. Environ. Microb., 68, 5042-5050, 2002.

Or, D., Smets, B. F., Wraith, J. M., Dechesne, A., and Friedman, S. P.: Physical constraints affecting bacterial habitats and activity in unsaturated porous media - a review, Adv. Water Resour., 30, 1505-1527, 2007.

Patil, R. S., Ghormade, V., and Deshpande, M. V.: Chitinolytic enzymes: an exploration, Enzyme Microb. Tech., 26, 473-483, 2000.

Peter, H., Beier, S., Bertilsson, S., Lindström, E. S., Langenheder, S., and Tranvik, L. J.: Function-specific response to depletion of microbial diversity, ISME J., 5, 351-361, 2011.

Pett-Ridge, J. and Firestone, M. K.: Redox fluctuation structures microbial communities in a wet tropical soil, Appl. Environ. Microb., 71, 6998-7007, 2005.

Picek, T., Šimek, M., and Šantrůěková, H.: Microbial responses to fluctuation of soil aeration status and redox conditions, Biol. Fert. Soils, 31, 315-322, 2000.

Rabus, R., Gade, D., Helbig, R., Bauer, M., Glöckner, F. O., Kube, M., Schlesner, H., Reinhardt, R., and Amann, R.: Analysis of $N$-acetylglucosamine metabolism in the marine bacterium Pirellula sp. strain 1 by a proteomic approach, Proteomics, 2, 649-655, 2002.

Raafat, D., von Bargen, K., Haas, A., and Sahl, H. G.: Insights into the mode of action of chitosan as an antibacterial compound, Appl. Environ. Microb., 74, 3764-3773, 2008.

Ramaiah, N., Hill, R. T., Chun, J., Ravel, J., Matte, M. H., Straube, W. L., and Colwell, R. R.: Use of a chiA probe for detection of chitinase genes in bacteria from the Chesapeake Bay, FEMS Microbiol. Ecol., 34, 63-71, 2000.

Saito, A., Fujii, T., and Miyashita, K.: Distribution and evolution of chitinase genes in Streptomyces species: involvement of geneduplication and domain-deletion, Anton. Leeuw. Int. J. G., 84, 7-16, 2003.

Sato, K., Azama, Y., Nogawa, M., Taguchi, G., and Shimosaka, M.: Analysis of a change in bacterial community in different envi- 
ronments with addition of chitin or chitosan, J. Biosci. Bioeng., 109, 472-478, 2010.

Schellenberger, S., Kolb, S., and Drake, H. L.: Metabolic responses of novel cellulolytic and saccharolytic agricultural soil Bacteria to oxygen, Environ. Microbiol., 12, 845-861, 2010.

Schellenberger, S., Drake, H. L., and Kolb, S.: Functionally redundant cellobiose-degrading soil bacteria respond differentially to oxygen, Appl. Environ. Microb., 77, 6043-6048, 2011.

Schellenberger, S., Drake, H. L., and Kolb, S.: Impairment of cellulose- and cellobiose-degrading soil Bacteria by two acidic herbicides, FEMS Microbiol. Lett., 327, 60-65, 2012.

Schlesner, H.: The development of media suitable for the microorganisms morphologically resembling Planctomyces spp., Pirellula spp., and other Planctomycetales from various aquatic habitats using dilute media, Syst. Appl. Microbiol., 17, 135-145, 1994.

Schloss, P. D. and Handelsman, J.: Introducing DOTUR, a computer program for defining operational taxonomic units and estimating species richness, Appl. Environ. Microb., 71, 1501-1506, 2005.

Schulten, H. R. and Schnitzer, M.: The chemistry of soil organic nitrogen: a review, Biol. Fert. Soils, 26, 1-15, 1998.

Schütte, U. M. E., Abdo, Z., Bent, S. J., Shyu, C., Williams, C. J., Pierson, J. D., and Forney, L. J.: Advances in the use of terminal restriction fragment length polymorphism (T-RFLP) analysis of 16S rRNA genes to characterize microbial communities, Appl. Microbiol. Biot., 80, 365-380, 2008.

Seidl, V.: Chitinases of filamentous fungi: a large group of diverse proteins with multiple physiological functions, Fungal Biol. Rev., 22, 36-42, 2008.

Šimůnek, J., Brandysová, V., Koppová, I., and Šimůnek Jr., J.: The antimicrobial action of chitosan, low molar mass chitosan, and chitooligosaccharides on human colonic bacteria, Folia Microbiol., 57, 341-345, 2012.

Someya, N., Ikeda, S., Morohoshi, T., Tsujimoto, M. N., Yoshida, T., Sawada, H., Ikeda, T., and Tsuchiay, K.: Diversity of culturable chitinolytic bacteria from rhizospheres of agronomic plants in Japan, Microbes Environ., 26, 7-14, 2011.

Sommer, M., Wehrhan, M., Zipprich, M., Weller, U., Castell, W., Ehrich, S., Tandler, B., and Selige, T.: Hierarchical data fusion for mapping soil units at field scale, Geoderma, 112, 179-196, 2003.

Suzuki, K., Taiyoji, M., Sugawara, N., Nikaidou, N., Henrissat, B., and Watanabe, T.: The third chitinase gene $($ chiC) of Serratia marcescens 2170 and the relationship of its product to other bacterial chitinases, Biochem. J., 343, 587-596, 1999.

Tamura, H., Goto, K., Yotsuyan, T., and Nagayama, M.: Spectrophotometric determination of iron (II) with 1,10phenanthroline in presence of large amounts of iron (III), Talanta, 21, 314-318, 1974.
Tamura, K., Peterson, D., Peterson, N., Stecher, G., Nei, M., and Kumar, S.: MEGA5: molecular evolutionary genetics analysis using maximum likelihood, evolutionary distance, and maximum parsimony methods, Mol. Biol. Evol., 28, 2731-2739, 2011.

Terahara, T., Ikeda, S., Noritake, C., Minamisawa, K., Ando, K., Tsuneda, S., and Harayama, S.: Molecular diversity of bacterial chitinases in arable soils and the effects of environmental factors on the chitinolytic bacterial community, Soil Biol. Biochem., 41, 473-480, 2009.

Tracey, M. V.: Chitinase in some basidiomycetes, Biochem. J., 61, 579-586, 1955.

Wagner, C., Griesshammer, A., and Drake, H. L.: Acetogenic capacities and the anaerobic turnover of carbon in a kansas prairie soil, Appl. Environ. Microb., 62, 494-500, 1996.

Ward, N. L., Challacombe, J. F., Janssen, P. H., Henrissat, B., Coutinho, P. M., Wu, M., Xie, G., Haft, D. H., Sait, M., Badger, J., Barabote, R. D., Bradley, B., Brettin, T. S., Brinkac, L. M., Bruce, D., Creasy, T., Daugherty, S. C., Davidsen, T. M., DeBoy, R. T., Detter, J. C., Dodson, R. J., Durkin, A. S., Ganapathy, A., Gwinn-Giglio, M., Han, C. S., Khouri, H., Kiss, H., Kothari, S. P., Madupu, R., Nelson, K. E., Nelson, W. C., Paulsen, I., Penn, K., Ren, Q., Rosovitz, M. J., Selengut, J. D., Shrivastava, S., Sullivan, S. A., Tapia, R., Thompson, L. S., Watkins, K. L., Yang, Q., Yu, C., Zafar, N., Zhou, L., and Kuske, C. R.: Three genomes from the phylum Acidobacteria provide insight into the lifestyles of these microorganisms in soils, Appl. Environ. Microb., 75, 2046-2056, 2009.

White, D.: The physiology and biochemistry of prokaryotes, 3rd edn., Oxford University Press, New York, USA, 383-403, 2007.

Williamson, N., Brian, P., and Wellington, E. M. H.: Molecular detection of bacterial and streptomycete chitinases in the environment, Anton. Leeuw. Int. J. G., 78, 315-321, 2000.

Wüst, P. K., Horn, M. A., and Drake, H. L.: In situ hydrogen and nitrous oxide as indicators of concomitant fermentation and denitrification in the alimentary canal of the earthworm Lumbricus terrestris, Appl. Environ. Microb., 75, 1852-1859, 2009.

Xiao, X., Yin, X., Lin, J., Sun, L., You, Z., Wang, P., and Wang, F.: Chitinase genes in lake sediments of Ardley Island, Antarctica, Appl. Environ. Microbiol., 71, 7904-7909, 2005.

Yang, H.-C., Im, W.-T., An, D.-S., Park, W.-S., Kim, I. S., and Lee, S.-T.: Silvimonas terrae gen. nov., sp. nov., a novel chitindegrading facultative anaerobe belonging to the "Betaproteobacteria”, Int. J. Syst. Evol. Micr., 55, 2329-2332, 2005.

Yaroslavtsev, A. M., Manucharova, N. A., Stepanov, A. L., Zvyagintsev, D. G., and Sudnitsyn, I. I.: Microbial destruction of chitin in soils under different moisture conditions, Eurasian Soil Sci.+, 42, 797-806, 2009. 